\title{
Philosophy and the Question of Social Relevance
}

\section{Adefarasin VO*}

Department of Philosophy, Olabisi Onabanjo University, Nigeria

*Corresponding author: Dr. Adefarasin VO, Department of Philosophy, Olabisi Onabanjo University, Ago-Iwoye, Nigeria, Tel: 08033907552; Email: adefarasinvo@yahoo.com

\section{Research article}

Volume 3 Issue 3

Received Date: August 06, 2020

Published Date: September 17, 2020

DOI: $10.23880 /$ phij-16000148

\section{Abstract}

The paper argues the thesis that Philosophy is relevant to our society. This is against the general erroneous and misconception that Philosophy, being an abstract discipline, has no practical relevance on our lives. The Anglo-Saxon analytic tradition lends support to this misconception by reducing Philosophy to analysis alone. As it has been conceived and developed in the West, and elsewhere, and in our contemporary society through the Ages, Philosophy has played and will continue to play vital roles in the development of our society. In order to achieve its intended objective therefore, the paper discusses meaning and definition of Philosophy, branches of Philosophy, "the ten commandments" of Philosophy. The paper concludes that Philosophy contributes meaningfully to the growth of any society.

Keyword: Philosophy; Qquestion; Social relevance

\section{Introduction}

Going by the title of this paper, 'Philosophy and the question of relevance' it shows the fact that Philosophy must serve humanity. It implies that Philosophy has some fundamental roles to play in human society and that its roles can't be over-emphasized or relegated to the background.

There are some people who think that Philosophy is such a discipline with little or no relevance to human life or society. Ogbinaka [1] asks the following fundamental questions: Why should one be a philosopher? Of what use is a philosopher and 'philosophies' to humankind? Can one really be glad that one's child is pursuing a university course in Philosophy? These questions are crucial in very many ways. This view is misleading, it expresses an utter ignorance of what Philosophy is all about. Our task in this paper is to bring out the importance of Philosophy as an intellectual enterprise.

This paper seeks to correct the erroneous impression that Philosophy is irrelevant to the challenge of transforming the situation of the human society. This paper is indeed an attempt to vindicate the claim of Philosophy that only a critical and rigorous enquiry can put a society on the path of genuine and sustainable transformation. The paper will further demonstrate through arguments that the precarious situation of the African society and the predicament of the global community are due to the disregard of the philosophical spirit. The paper will finally maintain that the adoption of the philosophical temperament, of a rigorous, critical and painstaking planning of the African society, will expedite the resolution of the prevailing African crisis. It will also argue that without the philosophical temper, the goodies presented to the global community by the scientific culture could become a burden with the prevailing uncontrolled explorative tendencies of modern technology.

The anxiety for the resolution of the African crisis and the excitement about the material transformation created by the scientific and technological revolution in the Western dominated global World made both the African and the global societies to disregard academic disciplines that have only remote, not readily visible utilitarian value for the ailing societies, like the philosophy discipline. To ignore Philosophy because its relevance is not easily discernable, is to fail to realize the very strong connection between 


\section{Philosophy International Journal}

thought and practice. And to do that is to invite disaster, whether physically, as we have it in Africa, or psychologically, as we feel it in the Western dominated global society. This is the reason why this paper is titled "Philosophy and the Question of Social Relevance".

The discipline of Philosophy as we have said is a tragic figure, constantly being harassed and with its relevance being questioned not only by outsiders, but, even by the practitioners of the vocation. The tragic fate of the philosophical discipline is a dual situation. The sciences, the social sciences and even the remaining humanistic disciplines that Philosophy conceived and produced at a time in the history of Western scholarly tradition is now in conspiracy with the policy makers to ensure that the mother discipline is finally shown the way out from the concert of intellectual disciplines. Still on the relevance of philosophy, it must be borne in mind that if you keep a beautiful young female dog in your house or compound, within one week you will notice at least one male dog milling around your compound. Similarly, if you have a beautiful young daughter, sister, or niece in your house, sooner or later your house will play host to young men. Philosophy is therefore the apple of the eyes of other disciplines.

\section{Meaning and Definitions of Philosophy}

From the outset, it is expedient and imperative to note that Philosophy has no widely acceptable definition and as there are scholars of Philosophy, so also, there are avalanche definitions of Philosophy. But, a word of warning is apposite; the mere fact that Philosophy does not have any generally acceptable definition, does not mean, denote, connote or portend that it cannot be defined. Omoregbe [2] says "if you ask ten different Philosophers what Philosophy is, you are likely to get ten different answers. The simple question "what is Philosophy? is very difficult to answer. A person who for the first time tries to find out what Philosophy is, is often disappointed to learn that there is no universally accepted definition of Philosophy. Philosophers themselves disagree on what Philosophy is or how it should be defined. It seems strange that professional philosophers themselves do not agree on the nature, scope and definition of their discipline. Philosophy as being conceived, described or defined the philosopher as a man whose passion is to seek the truth, a man "whose heart is fixed on reality."

From these descriptions of Philosophy by philosophers (both ancient and contemporary), we can see that there is no univocal conception of Philosophy. Different schools of Philosophy conceive Philosophy in different ways. While one school (represented by Jacque Maritain) says that Philosophy is par excellence metaphysics, another school (represented by A.J. Ayer) says that metaphysics is not Philosophy, and that metaphysical statements are meaningless statements. These philosophers disagree sharply on the question of the nature and scope of Philosophy. Philosophy according to Thomas Hobbes is only concerned with bodies, that is, material things and their casual relations. Philosophy is thus a discipline, the nature and scope of which is a problem in itself, for it is a critical discipline which does not exempt itself from its own criticism, but, applies its critical tool to itself. Hence, the very disagreement among philosophers about the nature of Philosophy is, ironically, part of Philosophy. Any conception or definition of Philosophy is subject to a philosophical criticism. Hence, no definition of Philosophy can be taken as the definition of Philosophy, for there is no such thing. It simply means that 'What is Philosophy?' is difficult to answer. Ogundowole [3] states that "It is often heard among students that there is no single universally accepted definition of Philosophy. Such a view is not infrequently stated even by academic Philosophers. The immediate impression you are likely to derive from this is perhaps that everyone is to his own kind of definition. Therefore, whatever definition you have, is inadequate, and that is it".

Momoh [4] adds that differences in the definitions or characterizations of Philosophy go back to differences in the perceptions of experiences and of cultures". Unah [5] admits that "there is no agreement among Philosophers as to the exact meaning or definition of Philosophy. This lack of agreement among Philosophers as to the meaning of their discipline need not make any of us unhappy. The nature of philosophical problems is such that Philosophers cannot but disagree".

Again, Ogbinaka [1] posits that "attempting to define Philosophy may be uncomfortable and embarrassing to both the beginner and his teacher. Nevertheless, this fact is not disturbing. Philosophers have found it easier to go into the business of philosophizing before ever attempting to define the business. The long historical span of the existence of Philosophy, the expanse of its scope and subject matter and importantly, the nature of the business of Philosophy itself has all created an intellectual environment that makes it difficult to provide a univocal as well as comprehensively acceptable definitions of Philosophy".

Moreover, Russell [6] says 'Philosophy arises from an unusually obstinate attempt to arrive at real knowledge. A man does not necessarily become a better Philosopher through knowing more scientific facts: it is principles and methods and general conceptions that he should learn from science if Philosophy is what interests him". Also, Bah [7] posits that "the Philosopher who says: 'I don't know what Philosophy is' wishes to stress not so much the lack of definition or the lack of contents, but rather, the generality of such definition, of vastness of the contents of Philosophy. 


\section{Philosophy International Journal}

The philosophical field is so broad that a definition of Philosophy may never be satisfactory to a layman, a student of Philosophy and a professional Philosopher".

All said and done, what then is Philosophy? Etymologically, Philosophy is derived from two Greek words Philo and Sophia. While Philo means love, Sophia means wisdom. From this, Philosophy can be defined as love of wisdom. It can be seen as the search for reality. Philosophy, goes with criticism, skepticism and refusal to believe unless on rational grounds. It goes with arguments, reflections, rationality and critical evaluation. In fact, argument is a decisive characteristic of Philosophy. Without intuitive argument and clarification, there is strictly no Philosophy [8].

In the same vein, it must be noted that, philosophers try to establish their theses by means of arguments. Arguments serve the same purpose for philosophers as proofs serve the mathematician or experimental demonstration serves the scientist or archaeological evidence and archival documents serve the historian.

According to Sodipo [9] "Philosophy is reflective and critical thinking about the concepts and principle which we use to organize our experience in morals, in religion, in social and political life, in law, in psychology, in history and the natural sciences". Once again, Philosophy can be defined thus: the rational explanation of reality and human experience, the general principle under which all facts could be explained; it is the science of the first principle of being; the presupposition of ultimate reality; the science of science.

\section{Branches of Philosophy}

Philosophy is a tree with many branches. Some of the branches are

Epistemology; it is the theory of knowledge. It explores or attempts to expose the power or ability, or capacity of the human mind to know reality. Some questions that are central to the study of epistemology are: What can we know? How can we know? Are we sure of what we know?

Metaphysics: The word "metaphysics" was the coinage of Andronicus of Rhodes who edited Aristotle's works. It derives from two Greek words: "meta" which means after and "physika" which means that within the confines of nature. It is the study of reality.

Axiology: This is the theory of value. It deals essentially with the value we can confer on human conduct and a work of art. Ethics or moral Philosophy: This deals with human conduct. It determines and prescribes the fundamental principles of morality. It studies the norms of human conduct and sometimes the language of morals. Logic: It is the analysis of the correct structure of reasoning. It is concerned with the provision of sound methods for distinguishing good from bad reasoning. The study of Logic provides a means of facilitating the attempt to develop well -argued positions and to evaluate critically the positions espouse by others. It helps us to assess how well our evidence (premises) support our claims (conclusions).

Political Philosophy which deals with the justification and limit of governmental control of individuals, the meaning of equality before the law, the basis of economic freedom, and many other problems concerning government.

Philosophy of Law: This area of Philosophy explores such topics as what law is, the kinds of law there are, the relationship of law and morality, the kinds of principles that should regulate punishment and criminal justice in general. Philosophy of Religion: What is religion? What does the concept "God" mean? What are the grounds for our belief or disbelief in God? How can religion contribute to the social and scientific developments? Other branches are: African Philosophy, Philosophy of mind, Philosophy of Science, Philosophy of Education among others.

\section{The "10 Commandments" of Philosophy}

1. Allow the spirit of wonder to flourish in your breast. Philosophy begins with deep wonder about the universe and about who we are, where we came from and where we are going, what is this life all about?

2. Doubt everything until the evidence convinces you of its truth. Be reasonably cautious, a moderate skeptic and suspicious of those who claim to have the truth.

3. Love the truth. 'Philosophy is the external search for truth, a search which inevitably fails and yet is never defeated, which continually eludes us, but which always guides us. This free, intellectual life of the mind is the noblest importance of the Western World; it is also the hope of our future.

4. Divide and conquer. Divide each problem and theory into its smallest essential components in order to analyse each unit carefully. This is the analytic method.

5. Collect and construct. Build a coherent argument or theory from component parts. One should move from simple, secured foundations to the complex and comprehensive.

6. Conjecture and refute. Make a complete survey of possible objections to your position, looking for counter examples and subtle mistakes. Following a suggestion of philosopher, Karl Popper, Philosophy is a system of conjecture and refutation, seek bold hypotheses and seek to find disconfirmations of your favorite positions. In this way, by a process of elimination, you will negatively and indirectly and gradually approach the truth.

7. Revise and rebuild. Be willing to revise, reject, and modify your beliefs and the degree with which you hold any belief. Acknowledge that you probably have many false beliefs and be grateful to those who correct 


\section{Philosophy International Journal}

you. This is the principle of falibilism, the thesis that we are very likely incorrect in many of our beliefs and has a tendency toward self-deception when considering objections to our position.

8. Seek simplicity. Prefer the simpler explanation to the more complex, all things being equal. This is the principle of parsimony, sometimes known as "Occam's Razor."

9. Live the truth. Appropriate your ideas in a personal way, so that even as the objective truth is a correspondence of the thought to the world, this lived truth is a correspondence of the thought to the thought.

10. Live the good. Let the practical conclusions of a philosophical reflection of the moral life inspire and motivate you to action. Let moral truth transform your life to that you shine like a jewel growing in its own light amidst the darkness of ignorance [10].

\section{The Relevance of Philosophy}

The fact cannot be disputed that Philosophy contributes fundamentally to any society. Hence, the practical relevance of Philosophy will now be delved into.

Momoh [11] captures the importance of Philosophy thus:

Philosophy is the base and the apex, the foundation, the ceiling and the roof of any civilization, any religion and science, indeed any discipline. Any culture, any way of life, corporate or individual, is anchored on a Philosophy, floats on a Philosophy and hangs on a Philosophy. Philosophy is the ultimate intellectual discipline, it is the queen, the king of all discipline. Whenever Philosophy is present, there is light, where it is absent, there is darkness. A people with its own Philosophy are liberated; a nation with its own Philosophy is a free nation. Without a Philosophy, a nation and a people are not just slaves, they are chained slaves, both in body, in mind and psyche.

In the same vein, Azenabor [12] avers that:

Philosophy is the mother of all disciplines; the other disciplines are intellectual descendants of Philosophy. This is precisely the reason why at the apex of any intellectual or academic enterprise, a Doctor of Philosophy (Ph.D) is awarded as a sign of continuity and paternalism.

In line with the above, Falola [13] declares that "the highest attainable degree in any field is a "philosophiae doctor" (doctor of philosophy). Philosophy being the grand "pattern of knowledge". This, without doubt, (emphasis mine) shows the relevance of philosophy.

Ali [14] also states that philosophy still holds on to its motheric position till date. This is justified by the fact that till date, the peak of any intellectual career still remains "The Ph.D.", that is, "Doctor of philosophy". Similarly, philosophy, till date, and as an academic discipline, still serves as a watch dog to all disciplines of intellectual endeavours.

In this respect, Philosophy has been described as the highest intellectual achievement of mankind. It is along this line that Unah [15] posits that "it is to provide parental protection, wisdom, guidance and discipline that the Philosophy department or faculty (in some cases) is retained in well-established universities all over the world. He goes further to declare that:

any university without a full fledge department or faculty of Philosophy, is an academic orphanage. We need not catalogue the social consequences of breeding orphans all over the place. You now have cultists and angry people nurtured with structured ignorance everywhere. The Federal Government through the National Universities Commission should direct all universities to establish departments of Philosophy without any further delay (Ibid, 23).

Furthermore, Owolabi [16] states that "Philosophy is the first academic discipline, and indeed, the progenitor of all other disciplines: This, without doubt, shows the importance of Philosophy". In order to lay emphasis on the relevance of Philosophy, Ogundowole [17] opines that "the Philosopher, as a matter of fact, is a jack of all trades and master of excellence. Hence - over of the world." Philosophy in the words of Falaiye [18] must change the world". Fadahunsi [19] shares the same view "philosophy is one of the moving forces shaping the development of societies".

Furthermore, in consonance with the above, Oladipo [20] avers that:

Philosophy has a crucial role to play in the production, clarification and propagation of the ideas and values that guide a thought and life of a people. Philosophy serves to challenge a people's established views of themselves and their condition as a precondition for defining or re-defining who they are and what they can be.

In addition, Balogun [21] maintains that "Philosophers shape the society and indeed the future by changing people's beliefs and habits of thought which in turn affect their actions". Accordingly, knowledge is necessary for action and action is necessary for survival, therefore, without philosophical consideration, life is without meaning.

At this juncture, it is important to underscore Ali's [14] views on the relevance of Philosophy to the society. Firstly, Philosophy provides grounds and proofs for abstract ideas to be utilized in solving the problems of life as in logical and mathematical sciences. Secondly, it serves as a tool for changing and/or revising the erroneously commonsensical views of life and of the world. Also, as an academic discipline, it is the underlying ideological framework in the world - 


\section{Philosophy International Journal}

order. This is why the failure of several contemporary African nations of today is as a result of the inability of our leaders to premise the future of African nations on ideological foundation. Nigeria, whither your ideology? Where is the Zikism of Nnamdi Azikwe? The Democratic Socialism and Egalitarianism of Obafemi Awolowo? The consciencism and the scientific socialism of Kwame Nkrumah? The Ujamaa of Nyerere? The Negritude of Leopold Senghor? These are philosophical ideological frameworks that have given Africa its focus at the independence period.

This is not all, the value of Philosophy is becoming more recognized in contemporary societies. For example, "If Philosophy had failed society in its history, it would have lost its place on the curriculum of universities" [22].

Similarly, Philosophy has an immense role to play in the society. The concern of the philosophers for values, goals and ends of human society, human activity and the means of achieving these, makes the philosopher better qualified to play the role of helping to determine societal values, development and progress. When the knowledge of Philosophy is applied to our societal life, it creates more enlightenment and gives meaning thereby enlarging our range of vision and perspective. Philosophy is a response to society and to social problems.

Philosophers can make policy makers to appreciate the deeper aspect of the problems of development - constantly reminding them for instance, of the true nature and dignity of society's greatest asset, namely, man himself and of his essential orientation to a goal above and beyond the state. Philosophy is an important tool of national development, where development is not seen as one dimensional, that is technological development only. There is also cultural development.

In most African societies, there is need for cultural authenticity and development. This is where Philosophy becomes useful to society, in the sense that it contributes greatly to the foundation of the standard of the culture of a society.

Furthermore, Philosophy is important in the areas of ideas. Every organization; be it medical, social, political, economic, educational, financial, industrial, media or even religious needs, ideas and Philosophy is the repository of ideas.

On a final note, Oladipo [23] asserts that Philosophy, like other disciplines has a practical mission. This can be summarized simply as "the elevation of mankind".

According to him, "elevation" as used in this context can be defined in terms of: enlightenment, open-mindedness, broadening of sensibilities, sensitivity to human principles (ideals), for instance, trust, tolerance, cooperation, compassion, and so on.

Similarly, Ogbinaka [1] avers that: "The emergence of psychology, sociology, political science, law, economics and the pure sciences is largely due to the efforts of philosophers such as Plato, David Hume, August Comte, Adam Smith, etc. Constitutionalism and democracy as political values rest largely on the intellectual efforts of philosophers like John Locke, Thomas Paine, Voltaire, Rousseau, De Montesquieu and many others. The organized labour movement, the progress made in a few States in the world can be attributed to the painstaking thoughts of Karl Marx and his collaborator, Fredrick Engels as well as their followers. Religion has benefited from philosophy. What Christianity is today is largely due to the efforts of the early fathers of the Church such as St. Augustine and St. Thomas Aquinas, Paul, the Apostle, who wrote the first Christian literature - the Epistles - was a stoic. Come to think of it, Plato's Academy and Aristotle's Leceum may be regarded as the first institutes of formal learning and they were bequeathed on to mankind by philosophers."

Again, Philosophy makes one critical and analytical, it gives one the power to interpret and draw out the consequences of issues. Philosophy could provide good and efficient problem solving skills and analytic-minded disposition to many issues that we confront in real life situations. It empowers one with the capacity to construct definitions, arguments, conceptsbuilding and problem-identification. Philosophy creates in its student a taxonomic attitude; making it possible for those who undergo a course in Philosophy to get imbued with organizational acumen. When confronted with such situations, they find in the tools of philosophy the competence to bring order into ideas and issues. The philosopher finds it easy to draw the boundaries in arguments and positions that are involved in contentious matters.

Again, "the search for standards and goals is an important part of the task of Philosophy" [24].

Also, philosophy helps us to be reasonable. Learning to be reasonable is of utmost importance because we all have to make choices and accomplish goals. Being reasonable enables us make good choices, accomplish our goals, live a better life, and become better people.

It also helps us to be moral: Morality is of the utmost importance because our decisions can have a powerful impact on ourselves and other. Our decisions can help or hurt people. We want fewer criminals, more people to help the poor, fewer CEOs who dump toxic waste in third world 


\section{Philosophy International Journal}

countries, more people to demand that the government stop handing out billions of dollars to oil companies in "subsidies," fewer corrupt cops and politicians, fewer judges who accept bribes, and so on.

It offers us knowledge: Philosophy has offered us the knowledge necessary to understand formal logic, develop natural science, discover highly plausible beliefs concerning being reasonable, highly plausible beliefs concerning morality, and more.

It is enjoyable: Why is philosophical knowledge so important? Again, it is important to be a reasonable and moral person. However, the knowledge we attain through philosophy is also enjoyable and perhaps even "good for its own sake." It might be worthy of learning just because it's a good kind of knowledge to have, even when it's not used for anything.

\section{It helps lead to many of the greatest achievements:} Philosophy itself is often the greatest human achievement in itself because human beings using their minds to reason well about complected issues includes some of the greatest work we've ever done.

It satisfies our sense of being a human being in a unique way: There is a sense of being a human being beyond our jobs, beyond our family, beyond our own benefit. There is a thirst for knowledge of the most difficult issues-reality, reasonableness, and ethics. We want to know how to make the world a better place and prioritize our lives in the best way possible. We want to know more about what it means to be a human being and to contemplate the majesty of our existence.

It helps us live a better life: Philosophy can help us live a better life in at least two ways. One, a "good life" can be, in part, a philosophical life. Two, it can help us decide how our lives can be improved.

It helps us identify deception: We know many religions are wrong and use manipulative techniques similar to cults. We know advertising agencies, propaganda, and politicians try to deceive people because they are often successful at doing so. We know that there is bad science that can't be trusted. There is good reasoning and bad reasoning and it's possible to learn more about the difference between the two. Once we learn the difference, we will be able to identify deception, avoid deception, and help others learn about it. Fighting against deception is part of making the world a better place. Those using deception to attain more money and power often hurt people in the process.

It helps us understand the history of thought: Philosophy can teach you the history that is often taken out of history books-the history of worldviews and thought itself. You can't know how we have "progressed" and attained the wonders of science and technology without knowing the history of philosophy.

It helps us be more creative: Philosophy can help us learn how to think more creatively. Learning about the answers people have thought of to life's greatest questions opens possibilities that you would have a very difficult time to realize on your own. Philosophers often contribute to the world by thinking in entirely new ways and offering entirely new answers-and you can learn to do so as well through example.

Philosophy can help make the world a better place: I think philosophy is of the utmost importance. The horrors of the world can often be attributable to a defect of the culture rather than just an isolated case of immorality. Our lack of reasonableness and a lack of moral knowledge is part of our culture. If philosophy becomes widespread and valued in enough people's lives, then our entire culture will be improved and the behavior of people within the culture will be improved. This is a holistic way to make the world a better place [25].

\section{Conclusion}

Let us harvest our thoughts in this section. Hence, from the foregoing, it is evident that Philosophy is indispensable in any attempt to better human conditions in contemporary Africa. We have attempted to outline the meaning and definitions of Philosophy, branches of Philosophy, the ten commandments of Philosophy and the social relevance of Philosophy to our contemporary society. It therefore goes without saying that it is an illusion, indeed a dangerous illusion to say that Philosophy has no value or contribution to our society. Again, it is misleading to view Philosophy as a theoretical discipline without obvious practical results. Philosophical ideas are dynamites. They have powerful influences on people's lives.

In furthering the horizon of the relevance of Philosophy, "the Philosophy of Plato and the Stoics had tremendous influence on the lives of millions of men in the post-Aristotelian period, especially during the Hellenistic period. It led to an ascetic attitude resulting in the renunciation of material possessions which were seen as sources of unhappiness. This Philosophy led millions of people to the conviction that the more a man amasses material possessions, the more unhappy he becomes. The philosophies of John Locke, Montesquieu, J.J. Rousseau, Hegel, Karl Marx were among the forces that shaped the Western society. The philosophical theories of John Locke, for example, are embedded in the 


\section{Philosophy International Journal}

American constitution and are to be seen at work whenever there is a dispute between the president and congress" [26].

In conclusion, the Kernel of our argument is that Philosophy performs for man and other disciplines fundamental functions. With all intents and purposes, honesty and candour, Philosophy, as we have shown, has a very healthy influence on the development of society and touches on every intellectual enterprise or discipline that is worth its salt [27].

\section{References}

1. Ogbinaka K (2010) A Window into Philosophy, Lagos: Joja Educational Research and Publishers Ltd.

2. Omoregbe J (1990) Knowing Philosophy, Lagos: Joja Educational Research and Publishers Ltd.

3. Ogundowole EK (2004) Philosophy and Society, Lagos: Correct Counsels Ltd.

4. Momoh CS (1991) Philosophy of a new Past and an Old Future, Auchi: Africa Philosophy project publications.

5. Unah J (1995) Essays in Philosophy, Lagos: Panaf Publishing Inc.

6. Russell B (1972) An Outline of Philosophy, London: Unwin Paperbacks.

7. Bah EDP (1997) Philosophy and Metaphysics: A Critical Introduction, Lagos: Obaroh \& Ogbinaka Publishers Ltd.

8. Wiredu K (1980) Philosophy and an African Culture, London: Cambridge University Press.

9. Sodipo O (1973) Philosophy and Culture, Ile-Ife: University of Ife press.

10. Louis P (1994) The Pursuit of Wisdom, California: Wadsworth publishing Company.

11. Momoh CS (2000) The Substance of African Philosophy, Auchi: African Philosophy Projects' Publications.

12. Azenabor G (2010) Understanding the Problems on African Philosophy, Lagos: First Academic Publishers.

13. Falola T (2015) "Humanities and Humanism: Secular
Vocations and their public outcomes". Faculty of Arts Open Lecture, Olabisi Onabanjo University, Ago-Iwoye.

14. Ali S (2012) Philosophy, African Philosophical Template and the Question of Man. Inaugural lecture delivered at Olabisi Onabanjo University, Ago-Iwoye.

15. Unah J (2006) "Even Nothing is Something”. An inaugural lecture delivered at the University of Lagos.

16. Owolabi K (2011) "My People Perish for Lack of Philosophy", An Inaugural lecture delivered at the University of Ibadan.

17. Ogundowole K (2008) "Inexhaustibility of Self-Reliance", An Inaugural lecture delivered at University of Lagos.

18. Falaiye $O$ (2012) A philosopher Interrogates African Polis: How can we get it Right? University of Lagos Inaugural Lecture Series.

19. Fadahunsi A (2003) Philosophy, Science and Technology. Ibadan: Hope publications.

20. Oladipo O (1999) "Philosophy and Culture" in Ayo Fadahunsi (ed) Philosophy and Society: An Introduction for Beginners, Ibadan: Hope publications.

21. Balogun 0 (2012) Philosophy in An African Culture: A Light in the Darkness. Inaugural Lecture delivered at Olabisi Onabanjo University, Ago-Iwoye.

22. Bodunrin PO (1990) "Philosophy as Pivot in Economic, Social and Political Re-Orientation", Imodoye: Journal of African Philosophy 1(7).

23. Oladipo 0 (2008) Thinking About Philosophy. A General Guide, Ibadan: Hope Publications.

24. Harold HT (1964) Living Issues in Philosophy: An Introductory Textbook, New York: D. Van Nostrand Co.

25. James WG (2012) Eleven Reasons Why Philosophy is Important.

26. Omoregbe J (2001) The Human Predicament: Has Human Life on Earth Any Ultimate Meaning? An Existential Inquiry. University of Lagos Inaugural Lecture Series.

27. Dewey J (1916) Democracy and Education, New York: Macmillan. 